Asia Pacific Journals

\title{
DESIGN AND ANALYSIS OF TRANSVERSE MOVEMENT ASSEMBLY OF VEHICLE FOR PARKING PURPOSE
}

\begin{tabular}{|c|c|}
\hline Abdul Ahad & R.A. Khan \\
Department of mechanical engineering & Department of Mechanical Engineering \\
NIET College of Engineering, & Jamia Millia Islamia \\
Greater Noida, India & New Delhi, India \\
er.abdulahad@gmail.com & rasheed_jmi @ hotmail.com \\
\hline
\end{tabular}

\begin{abstract}
Rapidly increasing number of automobiles on the roads has evolved the problem of parking. Due to the limited space or land available; this problem is increasing day by day. It is necessary to tackle this issue so that the hassles involved in parking of vehicle could be conquered. An attempt has been made to design a transverse movement assembly for the vehicles to overcome the bitterness encountered during parking as well as to enable the drivers to park their vehicles in parallel array. All of the components were designed and their three dimension models were created using solid works. The analysis of loads, stress and deformation was carried out using ANSYS V12.0. It was finally concluded that the designed model is safe and viable to work practically.
\end{abstract}

Keywords - Parking, hydraulic system, sprocket, transverse wheels, parallel parking.

\section{INTRODUCTION}

In many areas, especially urban areas, parking is a serious problem. Shortages of parking space, complaints about high parking tariffs and congestion due to visitors in search for a parking place are only a few examples of everyday parking problems. Many cities and urban areas recognize these problems, but the solution proves to be very complicated. Delhi, the capital of India is facing an acute transport management problem. This primary problem leads to many more secondary problems such as air pollution, high-energy consumption, congestion, loss of productivity, increase in death accident rates etc.

\section{OBJECTIVES OF STUDY}

- Primary objective: - Design \& Analysis of transverse movement assembly in vehicle for parking purposes.

- Additional objective: -Implementation of primary objective proposed design in vehicle.

\section{METHODOLOGY OF PRESENT WORK}

First step, different components that can be used in assembly will be identified. The mechanism presented in this project is composed mainly of 4 parts: new shaft, sprocket \& chain, hydraulic ram and wheel.

\section{A. General arrangement}

These parts are assembled together creating the mechanism. There are some commercial elements like the bearings or the screws that make possible the joint of these parts and their movements. The commercial elements do not appear physically. They are replaced by their effects in the mechanism. ANSYS Simulation allows these joint elements to simulate the behavior of the mechanism without creating a detailed geometry.

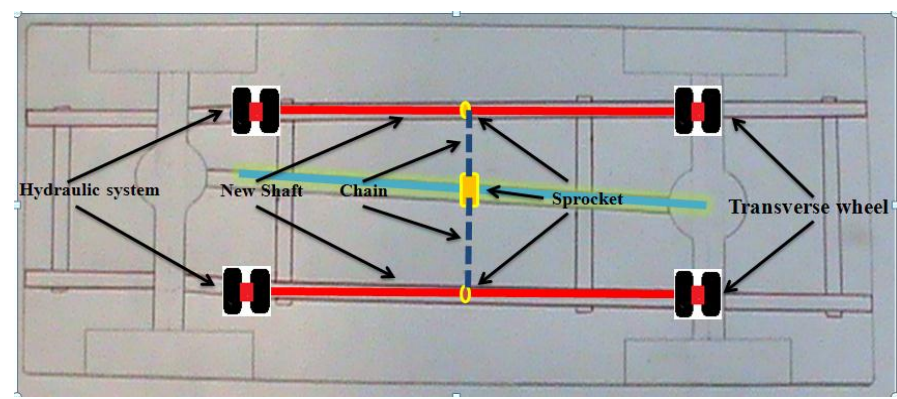

Fig. 1. General arrangement of different component

\section{B. Power transmission assembly}

This assembly is compounded by the shaft and the sprocket. The shaft and the sprocket have a rigid connection in the assembly. The shaft has transmitted the torque to the sprocket and it is connected to the new shaft by the chain.

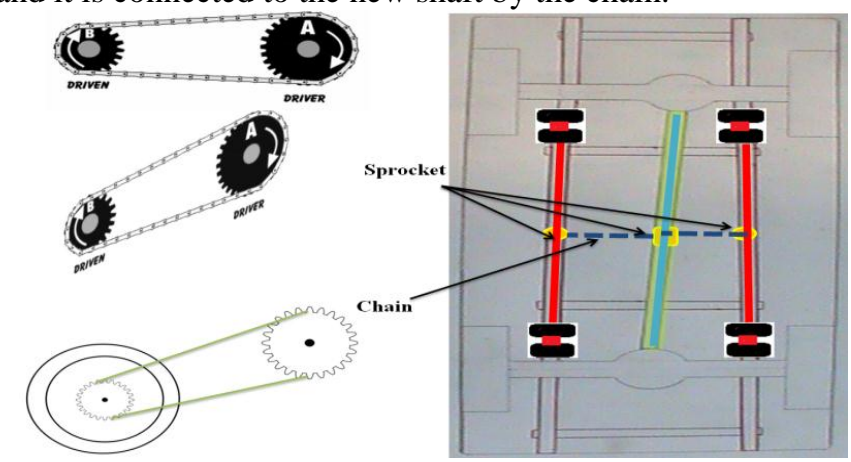

Fig. 2. Power transmission assembly

\section{Hydraulic system assembly}




\section{Asia Pacific Journals}

This assembly is compounded by the hydraulic cylinder and the vehicle chess. The hydraulic cylinder has fixed in bottom of the vehicle chess. The hydraulic ram moves up and down according to work required.

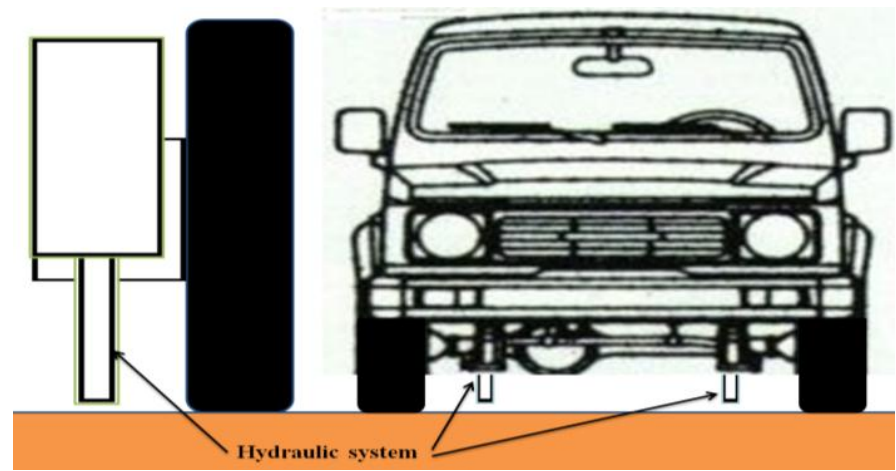

Fig. 3. Hydraulic system assembly

\section{Transverse wheel assembly}

Transverse wheel is connected with hydraulic ram. Transverse wheel is used for left and right movement.

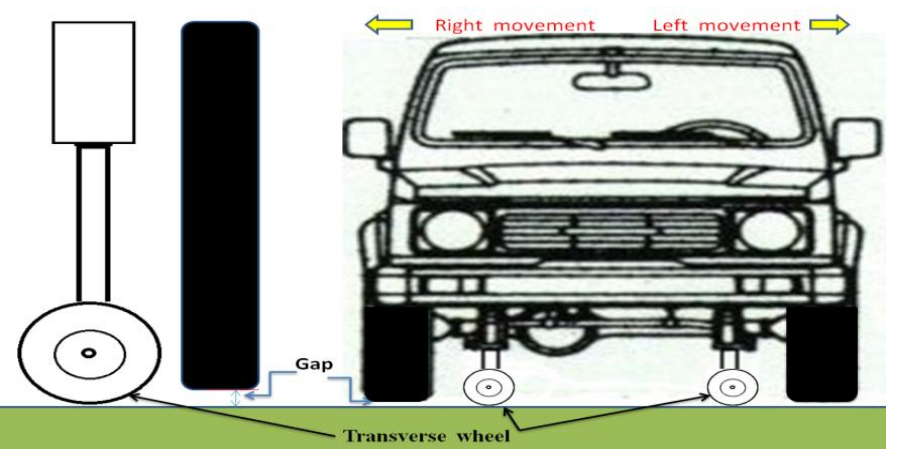

Fig. 4. Transverse wheel assembly

\section{DESIGN OF HYDRAULIC SYSTEM}

Hydraulic principles are used when designing hydraulic implement systems, steering systems, brake systems, power assisted steering, power train systems and automatic transmissions. Hydraulics plays a major role in mining, construction, agricultural and materials handling equipment. Hydraulics is used to operate implements to lift, push and move materials.

In hydraulic systems, forces that are applied by the liquid are transmitted to a mechanical mechanism. To understand how hydraulic systems operate it is necessary to understand the principles of hydraulics. Hydraulics is the study of liquids in motion and pressure in pipes and cylinders.

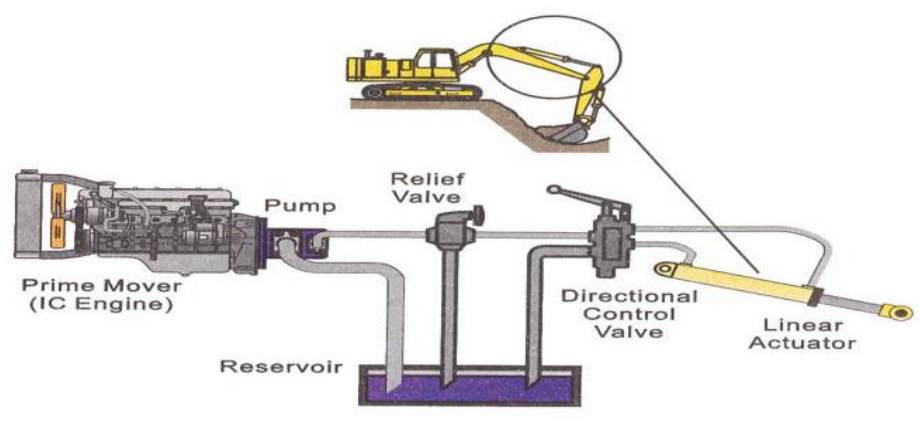

Fig. 5. Simplified Hydraulic Circuit

A complete hydraulic system consists of a reservoir of fluid, a hydraulic pump driven by an internal combustion (IC) engine or an electric motor, a system of valves to control and direct the output flow of the pump, and actuators that apply the forces to conduct the work being performed. Fig. 5 is a simplified illustration of these major components.

\section{DESIGN OF SHAFT}

Shafts form the important elements of machines. They are the elements that support rotating parts like gears and pulleys and in turn are themselves supported by bearings resting in the rigid machine housings. The shafts perform the function of transmitting power from one rotating member to another supported by it or connected to it. Thus, they are subjected to torque due to power transmission and bending moment due to reactions on the members that are supported by them. Shafts are to be distinguished from axles which also support rotating members but do not transmit power. Axles are thus subjected to only bending loads and not to the torque.

\section{A. Modal and design analysis}

Design Parameters: The design parameters for the shaft are follows.

Table I. The design parameters for the shaft

\begin{tabular}{|l|l|l|l|}
\hline Parameter of the shaft & Symbol & Value & Unit \\
\hline Diameter of shaft & $\mathrm{D}$ & 30 & $\mathrm{~mm}$ \\
\hline Length of shaft & $\mathrm{L}$ & 2400 & $\mathrm{~mm}$ \\
\hline
\end{tabular}

\section{B. Assumptions:}

1. The shaft rotates at a constant speed about its longitudinal axis.

2. The shaft has a uniform, circular cross section.

3. The shaft is perfectly balanced, i.e., at every cross section, the mass center coincides with the geometric center.

4. All damping and nonlinear effects are excluded.

\section{Modeling, Meshing and Boundary conditions for Design Analysis:}

ANSYS v12.0 software is used to determine the maximum torsional stress of the shaft. Firstly, a three dimensional solid shaft $2400 \mathrm{~mm}$ long and $30 \mathrm{~mm}$ in diameter is modeled. The surface boundary conditions are applied to the shaft model as shown in Figure 6. Cylindrical support is applied at both end shaft, $183 \mathrm{Nm}$ of torsion is applied on the mid of the shaft and 


\section{Asia Pacific Journals}

$7500 \mathrm{~N}$ load applied at the distance of $50 \mathrm{~mm}$ both end of the shaft.

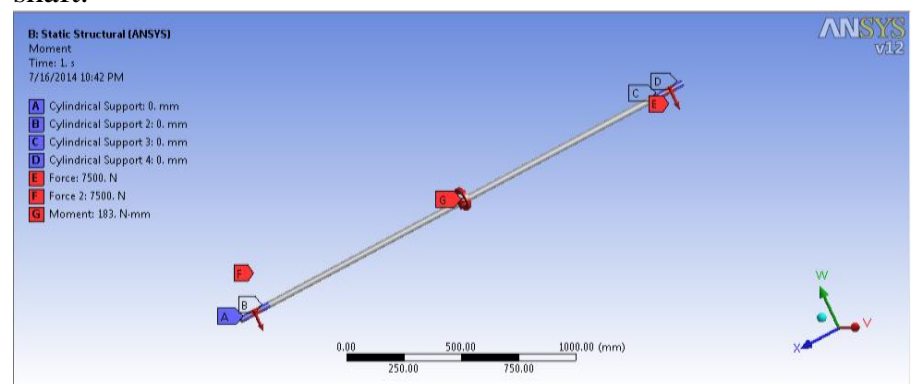

Fig. 6. ANSYS Model with boundary conditions

\section{A. Design Parameters:}

\section{DESIGN OF SPROCKET}

The design parameters for the sprocket are follows.

Table II. The design parameters for the Sprocket

\begin{tabular}{|l|c|c|c|}
\hline Parameter of the sprocket & Symbol & Value & Unit \\
\hline Diameter of sprocket & $\mathrm{D}$ & 80 & $\mathrm{~mm}$ \\
\hline Thickness of sprocket & $\mathrm{T}$ & 8 & $\mathrm{~mm}$ \\
\hline
\end{tabular}

B. Modeling, Meshing and Boundary conditions for Design Analysis:

ANSYS v12.0 software is used to determine the different type of stresses and deformation of the sprocket. Firstly, a three dimensional solid sprocket $8 \mathrm{~mm}$ thickness and $80 \mathrm{~mm}$ in diameter is modeled. The surface boundary conditions are applied to the sprocket model as shown in Fig.7. Fixed support is applied at the hub of the sprocket and $500 \mathrm{~N}$ of force is applied on the top teeth of the sprocket.

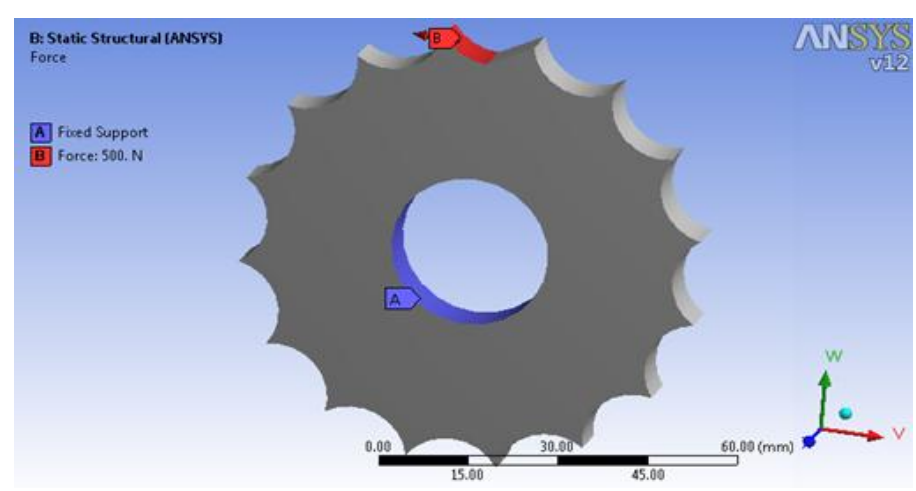

Fig. 7. ANSYS Model with boundary conditions

\section{Selection of Chain}

According to load and sprocket size the chain no. ISO-08B is suitable. This is a simplex type chain, its roller diameter is $12.8 \mathrm{~mm}$ and its breaking load is $18200 \mathrm{~N}$.

\section{DESIGN OF WHEEL}

\section{A. Modal and Design Analysis}

Specifications of Model Wheel: The design parameters for the wheel are follows.

Table III. The design parameters for the wheel

\begin{tabular}{|l|c|c|c|}
\hline Parameter of the wheel & Symbol & Value & Unit \\
\hline Diameter of wheel & $\mathrm{D}$ & 160 & $\mathrm{~mm}$ \\
\hline Thickness of wheel & $\mathrm{T}$ & 30 & $\mathrm{~mm}$ \\
\hline
\end{tabular}

Meshing and Boundary conditions for Design Analysis:

ANSYS v12.0 software is used to determine the different type of stresses and deformation of the wheel. Firstly, a three dimensional solid wheel $30 \mathrm{~mm}$ thickness and $160 \mathrm{~mm}$ in diameter is modeled. The surface boundary conditions are applied to the wheel model as shown in Figure8. Fixed support is applied at the hub of the wheel and $3750 \mathrm{~N}$ of force is applied on the lower surface of the wheel.

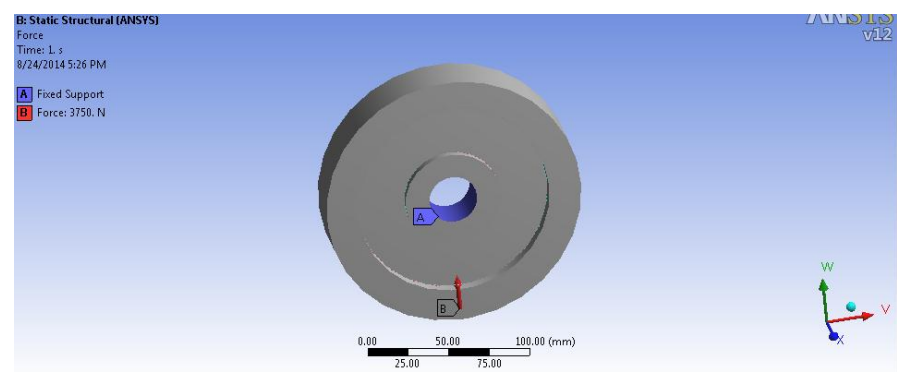

Fig. 8. ANSYS Model with boundary conditions

\section{CONCLUSIONS}

By designing the system and assembling we conclude that:

a) Transverse movement of vehicle is essential for parallel parking. It saves a lot of space. The vehicle can be driven from a parking lot if there is space from any of the four sides.

b) As there is need of the movement of adjacent vehicle so owners of the vehicle can take away the keys of their vehicle and the system enhances the security of vehicles and chances of theft and misuse are reduced as the vehicle is parked near to the place of work.

c) The system is also helpful at the time of changing the tyres.

d) From the above Study it can be conclude that, the stresses found out by analytical method. The main conclusion obtained from the present study of hydraulic system is that it is safe for $30000 \mathrm{~N}$ loads. The shaft of vehicle designed is safe for $3041.667 \mathrm{~N}$ loads and $183 \mathrm{Nm}$ torque. The sprocket and chain of vehicle designed is safe for $3041.667 \mathrm{~N}$ loads and 


\section{Asia Pacific Journals}

$183 \mathrm{Nm}$ torque. The wheel of vehicle designed is safe for $3750 \mathrm{~N}$ loads.

e) General arrangement of Transverse movement assembly vehicle is shown in Fig. 9.

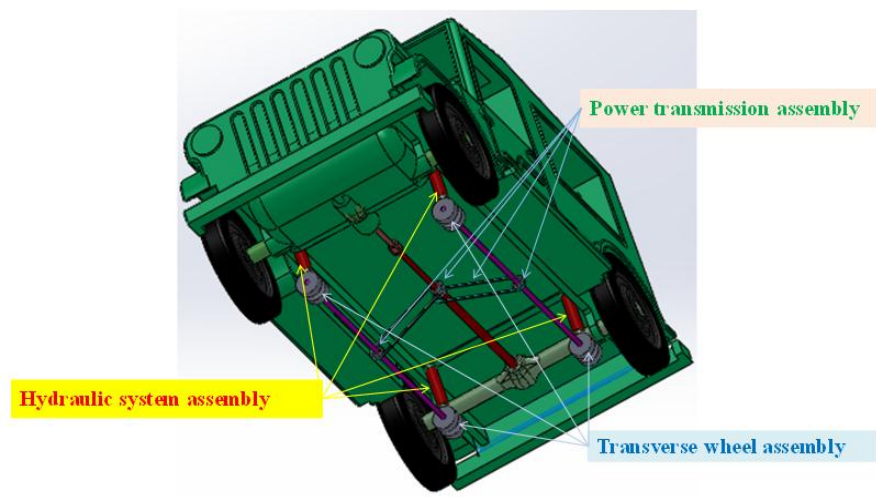

Fig. 9. General arrangement of Hydraulic system assembly, Transverse wheel assembly and Power transmission assembly

\section{References}

[1] Hitendrawasnik, Dr. R.D. Askhedkar, Dr.S.K.Choudhary "Design and Computer Simulation of Five Stack Semi-automatic Car Parking System, IJERIA, September 10, 2011.

[2] V. K. Jadon, Suresh Verma, "Machine Design Data Book $2^{\text {nd }}$ edition", I.K.International Publication, 2013.

[3] Callister, "Material Science and Engineering Book", WILEY INDIA Publication, 2013.

[4] Daniel P. Raymer, “Aircraft Design: A Conceptual Approach”, AIAA Education series, $2^{\text {nd }}$ ed, Washington, 1992. 